\title{
Employing Technology Acceptance Model (TAM) to Determine the Acceptance of Diagnostic System for Cervical Cancer Screening in Developing Countries
}

\author{
Shade Kuyoro \\ Babcock University \\ llisan, Ogun State, Nigeria
}

\author{
Kasali Funmilayo \\ Babcock University \\ llisan, Ogun State, Nigeria
}

\begin{abstract}
In recent times, contemporary hospitals continue to become smart by automating their administrative processes using up to date equipment and incorporating latest technological principles into their activities. It has been seen over the years that the area of medical diagnosis systems require the use of diagnostic systems as they have been proven to have led to increased diagnostic accuracy and relieve experts from routine tasks. The easiest way to prevent women from suffering and dying from Cancer of the cervix is through early detection of the Human Papilloma Virus hence the recommendation of Visual Inspection with Acetic acid (VIA) to be done in developing countries by the World Health Organization. There is need for systems that can assist health workers in confirmation of results gotten after VIA tests has been done on patients to reduce misdiagnosis and overtreatment but such systems need to be developed by putting users need into consideration. Evaluating users' acceptance of such systems is one of the most important metrics in ensuring the success of such systems as it helps to predict users' willingness to accept or reject them.
\end{abstract}

The Technology Acceptance Model (TAM) was used to evaluate the level of eagerness of users to use such systems and the measuring instrument was analyzed using SPSS version 21.0. A total of 150 respondents participated in this study with a response rate of $86 \%$. From the analysis, it was realized that a total of $80.7 \%$ of the sampled population subscribed to the use of diagnostic expert systems, $89.1 \%$ believed that the use of such systems will have a positive impact and $87.6 \%$ were willing to use it. The results of TAM indicated the willingness of users to use such systems, the need to repeat the study after executing the system in real life was suggested as users intention could change, and also to identify factual usage of the system. The work brought to light the impact of putting users' needs into consideration first since this increases user acceptability which could eventually lead to the success of such diagnostic systems at large.

\section{Keywords}

Expert System, Technology Acceptance Model, Cervical cancer

\section{INTRODUCTION}

With 528,000 new cases every year, cervical cancer is the fourth most common cancer affecting women worldwide, after breast, colorectal, and lung cancers; it is most notable in the lower resource countries of sub-Saharan Africa [17]. It ranks as the second most frequent cancer among women in Nigeria with crude incidence rate of 19.3 [19].
Some ways to reduce the prevalence of this disease include safer sex, cervical cancer vaccination and screening of the cervix to detect the presence of high risk Human Papilloma Virus (HPV) which left untreated leads to cancer of the cervix. Some screening measures include HPV testing, Papanicolaou testing (Pap smear), VIA and Visual Inspection with Lugous Iodine (VILI) screening method amongst others. In developing countries, screening for the cancer cells is mostly done using VIA and VILI method as a result of their screen and test approach, cost effectiveness and can be carried out using modest equipment and widely available consumables without the need for a laboratory infrastructure [15]. Presently, most developing countries face shortages of health workers who can accurately read and interpret diagnostic results of cervical cancer screening [2] which is the best, easiest and most cost effective way to prevent the disease hence the need for expert diagnostic systems.

Expert systems (ES) are a branch of applied artificial intelligence (AI), and were developed by the AI community in the mid-1960s. The basic idea behind ES is simply that expertise is transferred from a human to a computer. This knowledge is then stored in the computer and users call upon the computer for specific advice as needed. The computer can reason and arrive at a specific conclusion. Then like a human consultant, it gives advices and explains, if asked, the logic behind the advice [25]. Expert System, a core part of AI, is defined according to Edward Feigenbaum of Stanford University as "an intelligent computer program that uses knowledge and inference procedures to solve problems that are difficult enough to require significant human expertise for their solution". This definition is said to be one of the most widely accepted definition of Expert systems [8]. An Expert Support System (ESS) such as a Medical Diagnostic Support System (MDSS) [22] is a growing technology that is adept at increasing diagnostic decision accuracy by improving the natural capabilities of human diagnosticians in the complex process of medical diagnosis [27].

\section{TECHNOLOGY ACCEPTANCE MODEL}

One of the most significant factors that usually influences the success or failure of Information Technology (IT) adoption is the extent or degree in which IT systems are accepted by users [12] or rejected. User acceptance is defined as the willingness of the users to use IT which is designed to support tasks [7]. The reason why companies invest in new technologies is to reduce cost and improve efficiency but if users do not accept the systems, this means that organizations cannot benefit significantly from the new systems. On the other hand, if users accept new IT systems they become more willing to make use of the new systems [23]. Usability is a sign of 
information success, hence finding the reasons that motivate people to use new systems or understanding the source of resistance toward using new systems is important to both system designers and developers [16].

The use of IT in health care practices has increased recently [18]. A variety of IT systems such as clinical information systems, personal digital assistants, electronic patient records and other applications have gradually become established in the healthcare industry. Clinical IT applications in healthcare are regarded as a key element in improving the quality of medical care. The concern of having new clinical IT systems unused is still one of the biggest issues for the clinical IT developers [12]. According to Reference [13], they claimed that in recent years there has been a growing interest in the identification of factors that cause potential users to accept and take advantage of systems developed and implemented by others. With respect to individual intention to accept new technology, several studies have been conducted and eight theoretical models have been established: Theory of Reasoned Action (TRA), Technology Acceptance Model (TAM), Motivational Model (MM), Theory of Planned Behaviour (TPB), a combined Theory of Planned Behaviour/Technology Acceptance Model (C-TAM-TPB), Model of PC Utilization (MPCU), Innovation Diffusion Theory (IDT), and Social Cognitive Theory (SCT). Each model was developed to explain users' readiness to accept new information systems and technology [6].

Of these models, the most widely cited is that of Fred Davis who proposed the technological acceptance model (TAM) in his doctoral thesis done in 1985 at the MIT Sloan School of Management [10]. TAM predicts user acceptance of any technology is determined by two factors, perceived usefulness which is defined as the degree to which a user believes that using the system will enhance his or her performance and perceived ease of use which is defined as the degree to which the user believes that using the system will be free from effort [5]. The goal of TAM is to predict information system acceptance and diagnose design problems before users have any interaction with the new system.

Despite the large volume of studies in technology acceptance research, minor work has been done in the health care context [1]. This is a sign of a significant gap in this area. Based on a body of literature, TAM is the most influential IT adoption model and has been widely applied to explain IT acceptance process in different contexts [10]. Davis developed TAM based on TRA in 1989 to mainly explain technology use in various situations and cultures in order to increase user acceptance of systems. Many previous studies have adopted and expanded this model which has been empirically proven to have high validity as highlighted by [21] in their recently published article on Understanding the evolution of TAM. User acceptance is defined as the demonstrable willingness within a user group to employ information technology for the tasks it is designed to support [7] and it has been an important field of study for over two decades now [5].

\section{REVIEW OF RELATED WORKS}

Fred [9] in his research addressed why users accept or reject information systems and how user acceptance is usually affected by system design features using TAM. Using a field study of 112 users regarding two end user systems was conducted to test the hypothesized model through questionnaires and concluded that attitude toward using, perceived usefulness and perceived ease of use fully mediated the effect of system design features on usage. Thomas, Bengisu, Brian \& Jacqueline [24] developed a conceptual model for physicians' acceptance of online systems and tested the socio-work structure model using a nationwide survey of 141 physicians. Kai [11] used a mixed evaluation approach by combining quantitative developmental trajectory modelling with qualitative assessments to examine users' adoption of Clinical Reminder System (CRS) technology and acceptance behaviour. Bilal, Mohd \& Wan [4] investigated some of the factors that affect the use of EMRs in Jordan and consequently provided a well-informed inferences for decision makers to take into consideration so as to better implement future EMR systems. TAM was used to evaluate the measuring instruments administered in 7 Jordan hospitals and analyzed using descriptive statistics from SPSS software. From the analysis, it was realized that there is a significant relationship between new technology and perceived technology which led the researchers to believe that health care professionals tend to consider adopting new technology as a positive so long as it leads to increase in quality and efficiency. Linda [14] used an extended version of TAM to study hospital websites and concluded that all TAM related factors such as perceived usefulness, perceived ease of use, trust and privacy are all highly relevant to the context of ehealth. Pouyan, Murali, Naresh \& Hossain [20] identified some factors which influence healthcare professionals' adoption of clinical Information Technology (IT).

From different literatures, it is seen that the primary aim of TAM is to predict information systems acceptance and diagnose design problems before users have experience with the new system. It would be incorrect to believe that information systems acceptance theories and models predict equally well in other cultural settings especially in developing countries as the strength of the model may differ across diverse cultures and thus need to be practically investigated.

\section{METHOD}

The kind of data that was used for this research is primary data collected by the researcher and this was used to gain some insights into why users will be eager to accept a recent technology. To explore the factors that influence users' acceptance of expert systems, quantitative research in the form of questionnaire survey was conducted to meet the objectives of the research. The measuring scales were developed using psychometric scales and the variables consisted of Likert's scale. The reliability of the measuring instrument was done using Cronbach's alpha reliability coefficient for Likert-type scales. The researcher used statistical software package (SPSS version 21.0) to analyse the TAM data.

Sampling Technique: The data used in evaluating user awareness and acceptance of Cervipert was obtained from MeCure diagnostic center, a leading diagnostic center and Island General Maternity hospital, both in Lagos State, Nigeria. Purposive sampling was used in the selection of these two leading health centers so as to include places of interest and exclude those places that do not fit the particular purpose for which this research is being done. Random sampling which is a probabilistic method of sampling was now used in the selection of respondents.

\section{RESULTS AND DISCUSSION OF FINDINGS}

The sample of survey was majorly health workers such as medical students, doctors, nurses, pharmacists and other 
health workers. The total population of health workers in MeCure diagnostic center is about 200 and that of Island Maternity in approximately 400 making the total population size to be about 600 . The sampling frame used was the collection of the whole population that can be included in the research work and in this case, the population of health workers which is also 600 . The sample size was gotten by using the sample size calculator designed by Creative Research Systems which was chosen as a result of its accuracy and moreover, TopTenReviews which is an online platform that provides software, web services, electronics, video game, music and movie reviews selected this system as the best survey software of 2014 [26]. After analysis, the sample size was gotten to be 150 based on a confidence level of $95 \%$ as mostly used by researchers, confidence interval of 6.95 and a population size of 600 . By putting the confidence level and confidence interval together, then, it can be said that there is $95 \%$ certainty that the true percentage of the population lies between a certain confidence interval, for example, 87.6 of the sample surveyed were willing to use Cervipert which means that with a confidence interval of 6.95 , this implies that between 80.65 and 94.55 of the entire population were willing to use Cervipert.

Before administering the questionnaires a pilot study was done just to sensitize people on what a diagnostic expert system is, its advantages and limitations and also to know the present challenges health workers face in screening using the Visual Inspection with Acetic acid method. By gathering user perceptions of a system's usefulness and ease of use, software developers can more accurately assess whether that system will ultimately be accepted by users. Based on TAM, the following hypotheses were formulated for the study in order to assess the level of acceptance of Cervipert.

Note: Perceived ease of use (PEOU), Perceived usefulness (PU) and Behavioural attitude (BA)

- $\mathrm{H}_{0}$ : $\mathrm{PEOU}$ will have a significant positive influence on PU influence on $\mathrm{PU}$

$\mathrm{H}_{1}$ : PEOU will not have a significant positive

- $\mathrm{H}_{0}$ : PU will have a positive significant influence on BA

$\mathrm{H}_{1}$ : PU will not have a positive significant influence

on BA

- $\mathrm{H}_{0}$ : PEOU will have a significant positive influence on $\mathrm{BA}$

influence on $\mathrm{BA}$

$\mathrm{H}_{1}$ : PEOU will not have a significant positive

The measuring tool consists of 2 parts namely Section A and Section B. Section A deals with the demographic profile of health workers and Section B includes a five point Likert scale items with response ranging from five to one representing Strongly Agree (5), Agree (4), Undecided (3), Disagree (2) and Strongly Disagree (1), PU, PEOU and Attitude towards using Cervipert. The Cronbach's alpha value for the tool was evaluated to be 0.97 which depicts the tool as a very reliable one. 150 questionnaires were administered and 129 was returned which yields a response rate of $86 \%$.

\section{DISCUSSION AND ANALYSIS OF FINDINGS}

From the findings, it was evident that most of the subjects were female workers with a total of 72 representing $55.8 \%$ of the total population. Majority of the health workers belong to the age group of 30 to 39 years with a percentage of $41.9 \%$ and workers above 60 years having less than $2 \%$ of the whole respondents. It is clearly seen that majority of the health workers who responded had associate degrees with doctorate degree following behind with $25.6 \%$. Most of the health workers who took part in the study were nurses having $40.3 \%$ of the total samples surveyed followed by doctors having $34.9 \% .70 .5 \%$ of health workers who took part in the survey work in a hospital and $29.5 \%$ were from a diagnostic center. From the analysis of the measuring tool, it was realized that a total of $72.1 \%$ of the entire respondents never knew what a diagnostic expert system is until it was explained to them, $80.7 \%$ representing 104 of the total 129 respondents subscribed to the use of expert system to assist in cervical cancer screening with VIA result confirmation while $46.5 \%$ were apprehensive of using Cervipert based on system and information quality, $30.2 \%$ fear was based on cost, $9.3 \%$ chose trust, $11.6 \%$ chose security while $2.3 \%$ of the sample surveyed apprehension were based on political, social and economic reasons as although $87.6 \%$ of the sample surveyed were willing to use Cervipert if these factors are put into consideration at the design phase of the system as $89.1 \%$ of the population sampled believe that the use of Cervipert will have a positive impact by reducing the prevalence of cervical cancer in Nigerian women.

\section{Level of Acceptance of Cervipert}

Table 1: Assessment of Perceived Ease of Use (PEOU) among respondents

\begin{tabular}{|c|c|c|c|}
\hline PEOU & Mean & $\begin{array}{l}\text { Standard } \\
\text { Deviation }\end{array}$ & Mean $(\%)$ \\
\hline $\mathrm{PEOU}_{1}$ & 4.05 & 0.794 & 81.0 \\
\hline $\mathrm{PEOU}_{2}$ & 3.91 & 0.824 & 78.2 \\
\hline $\mathrm{PEOU}_{3}$ & 4.01 & 0.765 & 80.2 \\
\hline $\mathrm{PEOU}_{4}$ & 4.08 & 0.767 & 81.6 \\
\hline $\mathrm{PEOU}_{5}$ & 4.07 & 0.752 & 81.4 \\
\hline $\mathrm{PEOU}_{6}$ & 4.06 & 0.774 & 81.2 \\
\hline PEOU & 24.18 & & 80.6 \\
\hline
\end{tabular}

The overall mean score obtained by the respondents was $24.18(80.6 \%)$ in the construct of perceived ease of use, it was evidenced that there was a high PEOU among respondents.

Table 2: Assessment of Perceived Usefulness (PU) among respondents

\begin{tabular}{|l|l|l|l|}
\hline PU & Mean & $\begin{array}{l}\text { Standard } \\
\text { Deviation }\end{array}$ & Mean (\%) \\
\hline $\mathrm{PU}_{1}$ & 4.18 & 0.785 & 83.6 \\
\hline $\mathrm{PU}_{2}$ & 4.07 & 0.850 & 81.4 \\
\hline $\mathrm{PU}_{3}$ & 4.15 & 0.782 & 83.0 \\
\hline $\mathrm{PU}_{4}$ & 4.09 & 0.740 & 81.8 \\
\hline
\end{tabular}




\begin{tabular}{|l|l|l|l|}
\hline $\mathrm{PU}_{5}$ & 4.11 & 0.737 & 82.2 \\
\hline $\mathrm{PU}_{6}$ & 4.13 & 0.744 & 82.6 \\
\hline $\mathrm{PU}_{7}$ & 4.08 & 0.825 & 81.6 \\
\hline $\mathrm{PU}_{8}$ & 4.08 & 0.767 & 81.6 \\
\hline $\mathrm{PU}_{9}$ & 3.98 & 0.800 & 79.6 \\
\hline $\mathrm{PU}_{10}$ & 3.93 & 0.831 & 78.6 \\
\hline $\mathrm{PU}_{11}$ & 4.14 & 0.788 & 82.8 \\
\hline $\mathrm{PU}_{12}$ & 4.10 & 0.748 & 82.0 \\
\hline $\mathrm{PU}_{13}$ & 3.98 & 0.815 & 79.6 \\
\hline $\mathrm{PU}_{14}$ & 4.24 & 0.682 & 84.8 \\
\hline $\mathrm{PU}_{15}$ & 3.85 & 0.985 & 77.0 \\
\hline $\mathrm{PU}^{10}$ & 61.11 & & 81.5 \\
\hline
\end{tabular}

Table 4: Correlation between PEOU and PU

\begin{tabular}{|ll|r|r|}
\hline & \multicolumn{1}{|c|}{ PU } & \multicolumn{1}{c|}{ PEOU } \\
\hline \multirow{2}{*}{ PU } & Pearson Correlation & 1 & $.736^{* *}$ \\
& Sig. (2-tailed) & & .000 \\
& N & 129 & 129 \\
& Pearson Correlation & $.736^{* *}$ & 1 \\
PEOU & Sig. (2-tailed) & .000 & \\
& N & 129 & 129 \\
\hline
\end{tabular}

**. Correlation is significant at the 0.01 level (2-tailed).

Table 5: Correlation between PU and BA

The overall mean score obtained by the respondent was 61.11 $(81.5 \%)$ in the construct of PU, it was evidenced that there was high PU towards Cervipert.

Table 3: Assessment of Behavioural Attitude (BA) among respondents

\begin{tabular}{|l|l|l|l|}
\hline BA & Mean & $\begin{array}{l}\text { Standard } \\
\text { Deviation }\end{array}$ & Mean (\%) \\
\hline $\mathrm{BA}_{1}$ & 4.22 & 0.780 & 84.4 \\
\hline $\mathrm{BA}_{2}$ & 4.17 & 0.719 & 83.4 \\
\hline $\mathrm{BA}_{3}$ & 4.16 & 0.712 & 83.2 \\
\hline $\mathrm{BA}_{4}$ & 4.19 & 0.661 & 83.8 \\
\hline $\mathrm{BA}_{5}$ & 4.12 & 0.718 & 82.4 \\
\hline $\mathrm{BA}_{6}$ & 3.88 & 0.787 & 77.6 \\
\hline $\mathrm{BA}_{7}$ & 3.87 & 0.995 & 77.4 \\
\hline $\mathrm{BA}_{8}$ & 3.93 & 0.880 & 78.6 \\
\hline $\mathrm{BA}_{9}$ & 4.08 & 0.775 & 81.6 \\
\hline $\mathrm{BA}_{10}$ & 4.13 & 0.754 & 82.6 \\
\hline $\mathrm{BA}_{11}$ & 4.16 & 0.744 & 83.2 \\
\hline $\mathrm{BA}_{12}$ & 4.16 & 0.696 & 83.2 \\
\hline $\mathrm{BA}_{13}$ & 4.15 & 0.674 & 83.0 \\
\hline $\mathrm{BA}_{14}$ & 4.09 & 0.729 & 81.8 \\
\hline $\mathrm{BA}_{15}$ & 4.12 & 0.750 & 82.4 \\
\hline $\mathrm{BA}_{16}$ & 4.26 & 0.724 & 85.2 \\
\hline $\mathrm{BA}$ & 65.69 & & 82.11 \\
\hline
\end{tabular}

The overall behavioural attitude mean score was 65.69

$(82.11 \%)$ which evidenced a favourable attitude towards Cervipert.

Correlation between constructs of TAM 


\section{CONCLUSION}

For any system to be qualified as being successful, it is not just enough that it is easy to understand, aesthetically attractive, and other positive factors but it must have been readily accepted by end users and do what it was designed for efficiently and effectively. User acceptability has been identified as one of the major factors that can be used to evaluate the success of adoption of any diagnostic system. User acceptability was tested using the TAM model and after analysis, users were willing to accept Cervipert based on trust, cost effectiveness and high information quality as they believe that Cervipert could eventually reduce the prevalence of this disease at large especially in developing countries.

\section{LIMITATIONS AND FUTURE RESEARCH}

Although TAM is most widely accepted for many researchers but this study could be carried out in real settings after health workers might have used Cervipert for a designated period of time to ascertain the real acceptability and not just based on their attitude towards the system before they have any real experience with it. It is possible that attitude could differ after Cervipert is used .This will further enhance the testing of effectiveness of Cervipert, its usability as well as functionality and quality of information that it possesses.

Furthermore, it is suggested that a new model should be developed that would exploit the strengths of the TAM model and discard its weaknesses. For a work of such importance, more geopolitical zones should be considered in future to get a wider view about people's opinions and attitudes towards the adoption of a diagnostic expert systems in the domain of medicine.

\section{ACKNOWLEDGEMENT}

We acknowledge the contributions of MeCure diagnostic center and Island Maternity General Hospital health workers for their contributions towards the successful completion of this work.

\section{REFERENCES}

[1] Aggelidis, V. P., Chatzoglou, P. D. (2009). Using a modified technology acceptance model in hospitals: International Journal of Medical Informatics, Volume 78, Issue 2, Pg. 115-126

[2] Anorlu, R. I. (2008). Cervical cancer: the sub-Saharan African perspective; Reproductive health matter: Elsevier journal, PII: S0968-8080(08)32415-X, Vol 16, Issue 39, Pg. 44. www.rhmjournal.org.uk

[3] Babu, D., Kasthuri, G. (2013). Applying Technology Acceptance (TAM) model to determine the acceptance of Nursing Information System (NIS) for Computer Generated Nursing Care Plan among nurses: International Journal of Computer Trends and Technology (IJCTT), Vol. 4, Issue 8, ISSN: 2231-2803, http://www.ijcttjournal.org

[4] Bilal, A., Mohd, S. A., and Wan, R. (2011). Overcoming challenges to use Electronic Medical Records System (EMRs) in Jordan Hospitals: IJCSNS International Journal of Computer Science and Network Security, Vol. 11 , Issue 8

[5] Chuttur, M.Y. (2009). Overview of the Technology Acceptance Model: Origins, Developments and Future Directions," Indiana University, USA .Sprouts: Working
Papers on Information Systems, Vol. 9, Issue 37, http://sprouts.aisnet.org/9-37

[6] Davis, F.D., Bagozzi, R.P., Warshaw, P. R. (1992). Extrinsic and Intrinsic Motivation to Use Computers in the Workplace. Journal of Applied Social Psychology, Vol. 22, Issue14, Pg. 1111- 1132.

[7] Dillon, A. \& Morris, M. (1996). User acceptance of new information technology: theories and models in M.Williams (ed) Annual Review of information Science and Technology, Vol. 31, Medford NJ: Information Today, Pg. 3-32

[8] Emmanuel, C. O., Adekunle, Y. A. (2013). Basic Concepts of Expert System Shells and an Efficient Model for Knowledge Acquisition: International Journal of Science and Research (IJSR), India Online ISSN: 2319-7064 Vol 2 Issue 4, Pg. 554.

[9] Fred, D. (1991). User acceptance of information technology: system characteristics, user perceptions and behavioural impacts, Academic Press Limited, International Man-machine Studies Vol. 38, Pg. 475-487, ISBN 0020-7373.

[10] Hossain, L, de Silva, A. (2009). Exploring user acceptance of technology using social networks: Journal of High Technology Research, Vol. 20, Issue 1, Pg. 1-18

[11] Kai, Z. (2006). Design, Implementation, User Acceptance, and Evaluation of a Clinical Decision Support System for Evidence- Based Medicine Practice Carnegie Mellon University H. John Heinz III School of Public Policy and Management Pittsburgh, Pennsylvania 15213

[12] Kijsanayotin, B., Pannarunothai, S., Speedie, S. M. (2009). Factors influencing health information technology adoption in Thailand's community health centres: Applying the UTAUT model, International Journal Medical Informatics, Issue 79, Pg. 404-416.

[13] King, W. R., He, J. (2006). A meta-analysis of the technology acceptance model. Information and Management, Issue 43, Pg. 740-755

[14] Linda, M. G., Cynthia, I. \& Gloria, M. (2010). Exploring the technology adoption needs of patients using e-health: IGI Global, document available online at www. Igiglobal.com/chapter/exploring-technology-adoptionneeds-patients/49902

[15] Lynette, D., Michael, Q., Sankaranarayanan, R. (2006). Screening for cervical cancer in developing countries, Rlsevier Science direct Vaccine 24S3 S3/71S3/77

[16] Mathieson, (1991). Predicting user intention: comparing the technology acceptance model with theory of planned behaviour. Information Systems Research, Vol 2, Issue 3, Pg. 173-191

[17] National Cancer Institute. (2013). what is Cancer? Retrieved from http://www.cancer.gov/cancertopics/cancerlibrary/whatis-cancer Retrieved on 1/7/2014

[18] Obstfelder, A., Engeseth, K. H., Wynn, R. (2007). Characteristics of successfully implemented telemedical applications, Implement Sci. Vol. 2, Issue 25. 
[19] Odetola, T. D., Ekpo, K. (2012). Nigerian Women's Perceptions about Human Papilloma Virus Immunisations, Journal of Community Medicine Health Education, Vol. 2, Issue 11, Pg. 1, ISSN: 2161-0711, doi:10.4172/2161-0711.100019

[20] Pouyan, E., Murali, S., Naresh, K., Hossein, N. (2013). The Effect of Knowledge Sharing on Technology Acceptance among Physicians, Global Advanced Research Journal of Engineering, Technology and Innovation, ISSN: 2315-5124, Vol. 2, Issue 2, Pg. 048057, Available online at http://garj.org/garjeti/index.htm

[21] Priyanka, S., Ashok, K. (2013). Understanding the Evolution of Technology Acceptance Model: Computer Science and Management Research paper ISSN: 23217782, Vol 1, Issue 6, www.ijarcsms.com

[22] Sheng, O. R. L. (2000). Decision support for healthcare in a new information age, Decision Support Systems Vol. 30, Pg. 101-103

[23] Succi, M. J., Walter, Z. D. (1999). Theory of user acceptance of information technologies: An examination of health care professionals, 32nd Hawaii International Conference on System Sciences, Hawaii, IEEE Computer Society

[24] Thomas, A. H., Bengisu, T., Brian, H., Jacqueline, B. (2004). Use of Online Systems in Clinical Medical Assessments: An Analysis of Physician Acceptance of Online Disability Evaluation Systems, Proceedings of the 37th Hawaii International Conference on System Sciences

[25] Turban, E. \& Aronson, J. E. (2001). Decision support systems and intelligent systems, sixth Edition (6th Ed). Hong Kong: Prentice International Hall

[26] TopTenReviews, Sample size calculator, Retrieved from https://www.crunchbase.com/organization/toptenreviews

[27] West, D., Mangiameli, P. B., Rampal, R., West, V., (2003). Ensemble strategies for a medical diagnostic decision support system: A breast cancer diagnosis application, European Journal of Operational Research $162532-551$ 